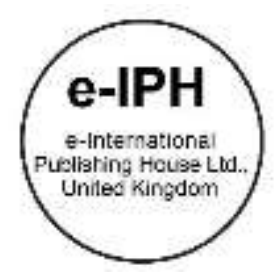

\title{
Towards Gender Inclusive Skill Development in Rural India: Factors that Inhibit and Facilitate Skill Women's Enrolment in Vocational Training
}

\author{
Srividya Sheshadri, Ayswarya Pradeep, Mamatha Chandran
}

Amrita Vishwa Vidyapeetham, Vallikav, 690546 Kerala, India

srividya.sheshadri@ammachilabs.org, pradeepayswarya@gmail.com, mamathachandranjr1996@gmail.com

\begin{abstract}
Women in rural India are the country's most underserved population regarding access to skill development opportunities. Despite rhetoric at the national and international policy levels acknowledging the dearth of female participation in vocational training and subsequently skilled labour in India, female enrolment remains low. A greater understanding of factors that facilitate and hinder women's enrolment in skill development programs, particularly in the current era of pro-skill development, where vocational training is highly subsidized, if not free of cost, is required to design effective interventions that are inclusive of this perpetually side-lined population. Towards developing this improved understanding, an exploratory qualitative study was conducted in the rural Indian village of Juna Khatiwada, Madhya Pradesh, where vocational training programs for women have been made available and accessible, free of cost. Semi-structured interviews and focused group discussions were conducted with 16 women of Juna Khatiwada. In addition to identifying factors that facilitate and inhibit enrolment among the target population, the study also revealed that women who did enrol and complete vocational training courses reported better coping with domestic economic challenges. Findings from this study serve to provide recommendations on the way forward in terms of skill development policy and practice that are more inclusive of women in rural Indian.
\end{abstract}

Keywords: Education and Training; Employment; Technical Vocational Rural India; Women

eISSN: 2398-4287@ 2021. The Authors. Published for AMER ABRA cE-Bs by e-International Publishing House, Ltd., UK. This is an open access article under the CC BYNC-ND license (http://creativecommons.org/licenses/by-nc-nd/4.0/). Peer-review under responsibility of AMER (Association of Malaysian Environment-Behaviour Researchers), ABRA (Association of Behavioural Researchers on Asians/Africans/Arabians) and cE-Bs (Centre for Environment-Behaviour Studies), Faculty of Architecture, Planning \& Surveying, Universiti Teknologi MARA, Malaysia.

DOI: https://doi.org/10.21834/ebpj.v6iSI4.3032

\subsection{Introduction}

Female labour force participation (FLFP) in India is on a steep decline and is among the lowest globally (UNDP, 2018). Within fewer than ten years, between 2006 and 2013, FLFP dropped ten percentage points (from 42.7 per cent to 31.1 per cent) and continues to decline (MOSPI, 2013). The devolving trend is particularly glaring amid an enduring era of economic growth. Women in India are less likely to pursue employment and demonstrate a more significant mismatch (compared to male counterparts) between the skills possessed and the jobs they demand (Fletcher et al., 2017). While the diminishing FLFP rate is often attributed to increased enrolment in higher education among girls, an ostensibly neglected point of discussion is the role skill development - or technical vocational education and training (TVET) potentially play in addressing the declining female labour participation trend, if at all (Fletcher et al., 2017; ILO 2016).

McKenzie and Company (2017) investigated the changing world of work amidst the emergent era of automation. The report noted that skills development was critical in periods of labour force transition and boosting FLFP. However, the report also found that enrolment of women in vocational education and training - like the diminishing FLFP trend, is similarly underwhelming (Fletcher et al., 2017). Approximately 2.5 per cent of India's labour force is formally skilled (World Bank, 2017). The proportion of skilled workers in India's labour force is among the lowest in the world (UNDP, 2018). Among those that received formal skill training, women in rural India are

eISSN: 2398-4287@ 2021. The Authors. Published for AMER ABRA CE-Bs by e-International Publishing House, Ltd., UK. This is an open access article under the CC BYNC-ND license (http://creativecommons.org/licenses/by-nc-nd/4.0/). Peer-review under responsibility of AMER (Association of Malaysian Environment-Behaviour Researchers), ABRA (Association of Behavioural Researchers on Asians/Africans/Arabians) and cE-Bs (Centre for Environment-Behaviour Studies), Faculty of Architecture, Planning \& Surveying, Universiti Teknologi MARA, Malaysia.

DOI: https://doi.org/10.21834/ebpj.v6iSI4.3032 
disproportionately under-represented at 1.7 per cent of the total population, as per the latest National Sample Survey (NSS) on Employment and Unemployment 2004 - 2005 (Srivastava, 2008).

In 2015, the United Nations recognized equal access to vocational education as one of its 17 Sustainable Development Goals (SDGs), stating: 4.5 By 2030, eliminate gender disparities in education and ensure equal access to all levels of education and vocational training for the vulnerable, including persons with disabilities, indigenous peoples and children in vulnerable situations. While education, including skill development for girls and women, has long been recognized as critical to human and community development, access and participation in such basic resources have been a challenge (Bhavani et al., 2017, Hartl, 2009). Cho et al. (2013) analyzed gender differences in the effects of vocational training and constraints women face. Factors that contribute to enrolment and dropout among women in vocational education were also studied. Social factors such as peer and family support were found to play a predominant role in enrolment, attendance and completion rates.

\subsection{The Setting}

This exploratory study was carried out in the rural village of Juna Kattiwada, Madhya Pradesh, where vocational training with a focus on women's empowerment has been available free of cost since 2016 through a non-governmental organization (NGO). A government-run vocational training institute located in the district of Alirajpur, where Juna Kattiwada is situated, has also been available before 2016. Despite direct access to TVET in the village and relative proximity to the government-run vocational training school, a sizeable percentage of women in Juni Kattiwada are yet to avail of the free courses being offered. A study on designing technology-based vocational education for rural villages in India found that contextualizing the intervention to the village's unique needs and socio-cultural norms was paramount in garnering acceptance among the marginalized community (Sachith et al., 2017). Accordingly, this study took a qualitative research approach to understand the factors invariably shaped by the village's socio-cultural norms that facilitate and inhibit enrollment in vocational education in Juna Kattiwada.

\subsection{Methodology}

The 16 women in the village have identified an approach to participate in the exploratory study. Respondents consisted of 8 women who self-reported that they had enrolled in vocational training and eight women who self-reported that they had never enrolled. Semistructured interviews were conducted with participants one-on-one, with the support of a local translator (from Hindi to the local dialect spoken in the village). While all participants consented to participate in the study, ten out of sixteen expressed discomfort with recording the interviews with an audio device but permitted the researchers to take notes. Therefore the data and results presented in this paper are based upon a combination of the researchers' field notes and transcribed data, where it was possible.

\subsection{Qualitative Analysis}

The analysis yielded seven themes through the following conventional coding process: 1) Transcribed and translated data (from Hindi to English) for 6 participants who consented to audio recording the interviews. 2) The researcher's field notes of interviews with ten respondents that did not consent to audio recording were typed up and prepared in a manner that would be compared to the transcribed data. 3) The data was analyzed through a repetitious process wherein 2 participants were compared, constituting eight sets of coded data. 4) The following code structure emerged from the eight sets of coded data - consisting of seven core themes pertinent to factors that enabling and inhibit enrolment in vocational education: Enabling Factors: Economic Independence, Source of Knowledge, Family Support and Inhibiting Factors: Perceived Risks, Low Perception of TVET, Mobility, Migration and Time Constraints

\subsection{Result and Discussion}

A summary of the respondent's socio-demographic background, provided through the semi-structured interview, is presented in Table 1.

In comparing the two groups of respondents, a more significant proportion of those who have not/never enrolled in vocational education (through the NGO or government institution) are considerably younger (in the 16 to 26 age group) than those who have enrolled. Given the concentration of younger women in the never/not-enrolled group, the fact that there is a more significant percentage of not-yet-married (75 per cent) in this group of respondents is plausible. The education attainment of those in the not/never-enrolled group is distinctively concentrated in the 3 rd grade and below category, compared to the enrolled group, where educational attainment is more dispersed. Those in the never/not-enrolled group are overall considerably less educated than those in the enrolled group. Semi-structured interviews with respondents revealed that a majority of respondents would have preferred to study further but were either challenged by their family's financial status or an expressed lack of family interest in educating their children further. The following excerpt from the researcher's field notes illustrates the experience a majority of women described around discontinuing education:

Respondent $\mathrm{K}$ - is not enrolled in vocational education and seasonally migrates to Gujarat for daily wage work. When she was a child, her father stopped her education partly because the family could not afford to send $\mathrm{K}$ to school and partly because her father believed it was time for $\mathrm{K}$ to focus on household duties. While researchers attempted to gauge the economic level of respondents, the majority of respondents were unable to provide details on the family's financial status. Alternatively, respondents were asked to share details on the numbers of daily-wage working members per household. The number of earning family members is also fairly differentiated between the two groups. Women enrolled in vocational training were found to belong to families where the number of earning members in the family ranged between one and two members, whereas a majority of those in not/never-enrolled group belonged to families where at least three members were earning an income. This information implies that families with more daily-wage earning members are more economically vulnerable than those with fewer working members. 
Table 1. Summary of Participants' Socio-Demographic Background

\begin{tabular}{|c|c|c|c|}
\hline \multicolumn{2}{|c|}{ Enrolied in TVET } & \multicolumn{2}{|l|}{ Noethever Enroled in TVET } \\
\hline Varieblo & Marcentage & Variabio & Nercentage \\
\hline \multicolumn{4}{|c|}{ No } \\
\hline $4-26$ & No & 1620 & ers. \\
\hline $27-50$ & y.s & $25-36$ & 128 \\
\hline $37-46$ & 0 & IDed & e \\
\hline \multirow[t]{2}{*}{47.56} & 25 & 47.68 & • \\
\hline & & Mared Bans & \\
\hline Marrinat & a.s & Marnest & 25 \\
\hline 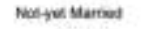 & 25 & Nob-Yat Startion & 76 \\
\hline \multirow[t]{2}{*}{ Widow } & $12 \mathrm{~s}$ & Weam & - \\
\hline & \multicolumn{2}{|c|}{ Leve if teasaten Cartivest } & \\
\hline a-3 gases & 125 & 0 - 3 graeses & 76 \\
\hline 3-il graseet & मs & 3- 4 grases & 25 \\
\hline $6-12$ gaden & 25 & $a-12$ gades & $\bullet$ \\
\hline Cologe & 12.5 & Colegn & • \\
\hline Posigratiaten & $\frac{12}{5}$ & Pestigratianan & - \\
\hline Daser-Wope Eanitu & Munterie & 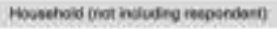 & \\
\hline 1 & 80 & 1 & 6 \\
\hline 2 & 373 & 2 & 25 \\
\hline Iand ubour & i2s & I Und atover & 72 \\
\hline
\end{tabular}

\subsection{Enabling Factors}

The following sub-section will now present data and analysis related to enabling factors in vocational education enrolment, as identified by the study's respondents.

\subsection{Economic independence}

Respondents in vocational training reported that their primary motivation to enrol was to secure a source of income independent of their spouse's or other family members. Respondents shared aspirations they had to become productively self-employed using skills they are currently learning or have learned in the past - opening a tailoring shop was a commonly reported plan. In addition to financial independence, respondents also shared that their reason for enrolling was primarily driven by their hope to contribute to the family household income as a way to build or support the family's capacity to survive economic crises (i.e. depleting savings, loan payments, etc.). The following excerpts from respondents enrolled in vocational education reveal the severity of the economic crisis and the hope that enrolling in vocational education will help alleviate financial stress:

"I believe enrolling in vocational training and earning a better income afterwards will help me support educating my children even at times of economic crisis." - Respondent $R$.

"I got enrolled in skill training so to repay my debts. My family deposited around 1 lakh rupees in the SHG, and they lost it. Hence I enrolled in skill training so that it will ensure myself and my family with a source of income." - Respondent $\mathrm{L}$.

\subsection{Source of Knowledge}

Avoid hyphenation at the end of a line. Symbols denoting vectors and matrices should be indicated in bold type. Scalar variable names should normally be expressed using italics. Weights and measures should be expressed in SI units. All non-standard abbreviations or symbols must be defined when first mentioned, or a glossary provided.

\begin{tabular}{rccc}
\multicolumn{2}{c}{ Table 2. Sources of Knowledge on Vocational Education and Training } \\
Enrolled & Percentage & Variable & Percentage \\
Variable & Source of knowledge & Not aware & 50 \\
& 0 & Own family & 0 \\
Not aware & 37.5 & Husband/in-laws & 12.5 \\
Own family & 37.5 & Friends/Others & 25
\end{tabular}

Enrolled respondents revealed that unanimously information about the opportunity to enrol in vocational education came from someone else (i.e. family, husband, friends, etc.) as opposed to their own self-discovery. Respondents shared that they felt comfortable pursuing enrollment solely because the information about vocational education came from a trusted source - such as their husband or other family members. In contrast, a majority of the not/never-enrolled group of respondents reported they did not know about opportunities for free or government-run vocational education in/near the 
village. Additionally, among this group, a smaller percentage had learned about vocational education from a relative or friend.

\subsection{Family support}

The way respondents learned about the provision of vocational education was found linked to perceived levels of family support among the respondents. As an extension of the source of knowledge, the majority of respondents enrolled in vocational training reported that they received support from their husbands and family to enrol and attend. Support was expressed in the form of motivation and other members of the family taking on some of the household duties normally performed by the respondent. Receiving help from family in transportation was also reported by some of the respondents who are farther from the training centre than others.

\subsection{Inhibiting Factors}

Despite the presence of vocational training in the village (where training is offered free of cost) and a government-run vocational training institute in proximity to the village, women's enrolment and participation in such resources remains a challenge for a sizeable portion of Juna Kattiwada village. This section will reveal some of the pressing challenges that respondents reported in attending vocational education.

\subsection{Perceived Risks}

A majority of respondents in the not/never-enrolled group reported that they seasonally migrate to Gujarat for daily wage work. As mentioned above, a majority of respondents expressed a lack of awareness of existing opportunities to learn vocational trades. However, even as they became aware of vocational training opportunities in the process of the semistructured interviews, respondents shared that the risk of compromising their current job opportunities would be too great. Failure to report for duty at the labour site invariably would risk chances of receiving work in the future. Another frequently reported perceived risk, especially among the married respondents, was the concern that they could not manage their household duties and attend courses at the same time.

\subsection{Low Perception of TVET}

Among the three or four respondents that had heard of vocational training and opportunities to enrol within/near the village prior to the semi-structured interview, all expressed a lack of trust in the effectiveness of further learning. A majority of the not/never-enrolled respondents expressed a lack of interest or motivation in pursuing vocational training, even when it was free of cost. The expressed lack of interest in vocational training was contrasted with a greater desire for guaranteed employment that was tangible through opportunities to earn an income through daily wage labour and migration.

\subsection{Migration and Time Constraints}

The nature of seasonal migration is such that the respondents are away from some months (mainly during off-cultivation periods) and then return to home base for other months of the year. Respondents shared that while vocational training may be possible during non-migrating months, cultivation and household duties take up a large part of the day - that there is little time left for anything else but sleep.

\subsection{Mobility}

A majority of respondents stated that travelling alone outside the home often required the permission of the family or husband. Accessing the government training centre is mainly challenged by the fact the women have restricted mobility. When asked whether access to the free training centre inside the village would pose a similar challenge, respondents felt mobility would not pose a problem. However, where mobility was not a grave concern, other reasons for not enrolling were often repeated, such as migration and time constraints and lack of family support. On the topic of mobility topic, one respondent who was recently married and enrolled in the vocational training course offered in the village shared, "I had heard about vocational training earlier, but my parents were not interested in sending me since it was very far away from my village. Since I got married to my husband from Juna Kattiwada, I find it easier to come and attend the training class."

\subsection{Conclusion}

The present study attempted an exploration of factors that enable and inhibit enrolment of women in vocational education, particularly when the opportunity bears no monetary cost and is available within steps of the home. Through this study, several themes emerged that shed light on factors that enable and inhibit participation in vocational training among women 
in rural India. While exploratory, the experiences shared by the respondents of Juna Kattiwada - those enrolled and not/never-enrolled in vocational education, bring into focus the extent to which family and community sources can influence a woman's enrolment in vocational training. Analysis of basic socio-demographic variables, the respondents' perceptions of vocational training and how they came to learn about training opportunities demonstrated the crucial role family support plays in women's enrolment. Through this study, it is apparent that perceived family support, in turn, leads to a greater willingness to enrol among the respondents. In fact, a majority of those enrolled in vocational education did so after learned about the opportunity through a husband, family member or close friend. On the other hand, half of the respondents those not/never-enrolled claimed to know little of vocational education opportunities prior to the study and a low perception of the benefits it might offer in the face of current employment opportunities that guarantee an income. These findings implicate the criticality of community outreach programs that spread awareness on the importance of skill development to the entire village or community.

\section{Acknowledgements}

The authors would like to thank the following individuals for their expertise and assistance throughout all aspects of our study and for their help in writing the manuscript.

\section{References}

Ahamad, T., Sinha, A., \& Shastri, R. K. (2016). Women Empowerment through Skills Development \& Vocational Education. SMS Journal of Entrepreneurship \& Innovation, 2(2), 76-81.

Andres, L., Dasgupta, B., Joseph, G., Abraham, V., \& Correia, M. (2017). Precarious drop: reassessing patterns of female labour force participation in India.

Bhavani, B., Sheshadri, S., \& Unnikrishnan, R. (2010, September). Vocational education technology: rural India. In Proceedings of the 1st Amrita ACM-W Celebration on Women in Computing in India (p. 21). ACM.

Bhavani, R. R., Sheshadri, S., \& Maciuika, L. A. (2017). Addressing the First Teachers: Education and Sustainable Development for Children, Families and Communities Through Vocational Education, Technology and Life Skills Training for Women. In Children and Sustainable Development (pp. 319-334). Springer, Cham.

Cho, Yoonyoung and Kalomba, Davie and Mobarak, Ahmed Mushfiq and Orozco, Victor, Gender Differences in the Effects of Vocational Training: Constraints on Women and Drop-Out Behavior (July 1, 2013). World Bank Policy Research Working Paper No.6545. Available at SSRN: https://ssrn.com/abstract=2298483

Coley, C. Sheshadri, S., Bhavani, R. R. (2015). Training India's first female toilet builders: An argument for improving sanitation through empowerment and social inclusion. 2015 International Conference on Sustainable Development (ICSD), NY, USA: Sustainable Development Solutions Network

Diwakar, Nitika \& Ahamad, Tauffiqu. (2015). Skills development of women through vocational training. International Journal of Applied Research 2394-5869. 1. 79-83.

Fletcher, E., Pande, R., \& Moore, C. M. T. (2017). Women and Work in India: Descriptive Evidence and a Review of Potential Policies.

Goel, V. P. (2009). Technical and Vocational Education and Training (TVET) Systemlin India for Sustainable Development,

Hartl, M. (2009). Technical and vocational education and training (TVET) and skills development for poverty reduction-do rural women benefit. Retrieved October 4, 2011.

ILO. (2016). India Labour Market Update. Retrieved from: http://www.ilo.org/wcmsp5/groups/public/---asia/---ro-bangkok/---sronew_delhi/documents/publication/wcms_496510.pdf.

KPMG. (2016). Human Resource and Skill Requirements in Building Construction Real Estate Sector (2013-17, 2017-22). Retrieved from: http://www.nsdcindia.org/sites/default/files/files/Building-Construction-Real-Estate.pdf on January 7, 2017.

McKenzie, D. (2017, March). How effective are active labour market policies in developing countries? a critical review of recent evidence. IZA Discussion Paper Series (10655).

Ministry of Statistics and Program Implementation Gol (2013). NSSO 2013-2014 Annual Report. Retrieved from: http://www.mospi.gov.in/sites/default/files/publication_reports/mospi_annual_report_2013-14.pdf

Sachith, K. P., Gopal, A., Muir, A., \& Bhavani, R. R. (2017, September). Contextualizing ICT Based Vocational Education for Rural Communities: Addressing Ethnographic Issues and Assessing Design Principles. In IFIP Conference on Human-Computer Interaction (pp. 3-12). Springer, Cham.

World Bank. South Asia Region. Human Development Unit. (2008). Skill development in India: the vocational education and training system

World Bank Group (2017). Skilling India. Retrieved from: http://www.worldbank.org/en/news/feature/2017/06/23/skilling-india

UNDP (2018). India Skills Report. Retrieved from: http://www.in.undp.org/content/india/en/home/library/poverty/india-skills-report-2018.html 